\title{
Editorial
}

\section{Evolução da revista texto \& contexto enfermagem, Florianópolis, sc, brasil - 1992-2011}

Dra. Maria Itayra Padilha

Editora da Texto \& Contexto Enfermagem. Professor Associado do Departamento de Enfermagem e do Programa de Pos-Graduacao em Enfermagem da Universidade Federal de Santa Catarina/Brasil.(PEN/UFSC).

Dra. Odaléa Maria Brüggemann

Editora de Submissao da Texto \& Contexto Enfermagem. Professora Adjunto do Departamento de Enfermagem e do PEN/ UFSC.

Dra. Denise Guerreiro Vieira da Silva

Editora de Selecao de Manuscritos da Texto \& Contexto Enfermagem. Professor Associado do Departamento de Enfermagem e do PEN/UFSC.

Dra. Marisa Monticelli

Editora de Texto e Layout da Texto \& Contexto Enfermagem. Professora Associado do Departamento de Enfermagem e do PEN/UFSC.

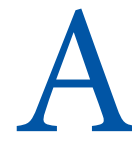

Revista Texto \& Contexto Enfermagem foi criada em 1992, pelo corpo docente do Programa de Pós-Graduação em Enfermagem (PEN) da Universidade Federal de Santa Catarina (UFSC), quando este percebeu a necessidade e relevância de promover mais um veículo de divulgação da produção científica brasileira. Na época, programas de pós-graduação em enfermagem eram escassos no território brasileiro, assim como, havia reduzido número de periódicos nacionais de divulgação, consumo e socialização da produção oriunda destes programas.

Após inúmeras discussões sobre fontes de financiamento, periodicidade, corpo editorial, indexação, seções a serem adotadas para a estruturação da revista, e também, qual seria o diferencial desta sobre as demais, o primeiro número foi editado em 1992, apenas com periodicidade semestral, devido aos parcos recursos existentes para sua manutenção. As pro- fessoras enfermeiras pioneiras deste processo, lideradas pela Dra. Ingrid Elsen, entenderam que uma nova revista no mercado editorial deveria apresentar um diferencial significativo, diante dos demais periódicos científicos da profissão, a fim de justificar sua existência e apresentar a tendência editorial da mesma. Assim, optaram por uma revista temática, visando atender à filosofia do PEN/UFSC, e oferecer à comunidade científica brasileira, um periódico com a abordagem de um objeto específico para cada um de seus números, e que seria discutido sob vários olhares e diferentes ângulos, permitindo assim, a possibilidade de um maior aprofundamento e consistência no tratamento das temáticas escolhidas.

Ao ser lançada no mercado editorial das revistas de enfermagem foi imediatamente aceita e as assinaturas, desde o seu início até o processo de acesso aos textos completos, em 2007, manteve-se entre 300 e 500 assinantes, o 
quê, para o publico consumidor brasileiro, podia ser considerado um "bom número". Como política de distribuição, eram editados, inicialmente, 1000 exemplares, os quais, além de serem enviados aos assinantes, também pela estratégia de permuta, eram encaminhados para todas as universidades públicas brasileiras, além de outras tantas estrangeiras, especialmente da America Latina.

Já em 1995, a revista tornou-se quadrimestral, sendo que o terceiro exemplar do ano foi denominado de "especial", a fim de registrar "os eventos significativos promovidos pelas(os) Enfermeiras(os) do Departamento de Enfermagem da UFSC, reunindo profissionais e discentes do Brasil e do exterior, em torno de um tema comum" (Elsen, 1995).

Ao completar 10 anos de existência, a Revista Texto \& Contexto Enfermagem estava indexada nas bases de dados LILACS(Literatura Latino Americana e do Caribe em Ciências da Saúde), BDENF(Banco de Dados de Enfermagem), e CINAHL(Cumulative Index to Nursing \& Allied Health Literature), e continuava pleiteando novas indexações, a fim de qualificar a revista, assim como, torná-la cada vez mais aberta para o mercado internacional.

A preocupação com a qualidade fez com que a indexação, a estruturação de um corpo editorial/consultores de excelência, a periodicidade e a regularidade, fossem sempre critérios considerados essenciais, em cada volume do periódico. Contudo, os critérios considerados complementares, que incluem autoria de artigos, assuntos/temáticas e normalização, além do impacto da Revista Texto \& Contexto Enfermagem, em nível nacional e internacional, sempre foram uma constante do PEN/ UFSC.

Um fator importante para os periódicos brasileiros em geral e, consequentemente, para a enfermagem, foi quando a Coordenação de Aperfeiçoamento de Pessoal de Nível Superior (CAPES) - um órgão governamental de nível central - criou, em 1998, o "Sistema Qualis" de avaliação da produção científica dos Programas de Pós-Graduação, e então, a partir de 2000, passou a utilizá-lo efetivamente como parte dos critérios de avaliação dos Programas de Pós-Graduação. Consequentemente, em novembro de 2000, a Comissão de Avaliação Continuada da CAPES - área de Enfermagem apresentou uma nova matriz de classificação dos periódicos em "Nacionais" e "Internacionais", com atribuição de conceitos, de acordo com os critérios estabelecidos pela comissão (Padilla \& Silva, 2002) .

No caso da Enfermagem, vale destacar, à época, o reduzido número de periódicos de circulação nacional, além de poucos assinantes, comparativamente ao número de enfermeiras registradas no país, como foi constatado por Mancia, Padilha e Ramos (2011), que, num universo de 10 revistas institucionais, em 1999, contava com apenas 1800 assinaturas, para um total de 80.000 enfermeiras brasileiras, o que representa apenas 2,25\% deste total.

Nesta mesma época, havia, no Brasil, apenas 22 periódicos de enfermagem, o que pode ser considerado irrisório, considerando a grande expansão dos Programas de Pós-Graduação no país, especialmente porque dentre estes, cerca de $20 \%$ estavam indexados internacionalmente. Por exemplo, em 1998, existiam 14 Programas de Pós-graduação em enfermagem (cerca de, e em 2011, este número foi ampliado para 50, ou seja, houve um aumento de $357,1 \%$, o que é extremamente relevante para o desenvolvimento da profissão de enfermagem, em termos de qualificação profissional (Ministerio da Educação, 2011).

A periodicidade da Revista Texto \& Con- 
texto Enfermagem também acompanhou esta evolução, sendo que em 1996 passou a ser quadrimestral e, em janeiro de 2003, trimestral, tal como permanece até o presente momento. Esta periodicidade veio atender à grande demanda de artigos submetidos e à necessária ampliação de oportunidades de veículos de disseminação do conhecimento produzido na área de enfermagem e contribuiu para a ampliação da sua indexação.

Assim, em 2005, a Texto \& Contexto Enfermagem já estava indexada nas seguintes bases de dados: LILACS, BDENF, CINAHL, CUIDEN - Index de Enfermería en Español, Fundacion Índex, Sistema Regional de Información em línea de Revistas Científicas de América Latina, el Caribe, España e Portugal (LATINDEX), e Red de Revistas Científicas de América Latina y el Caribe, Espana y Portugal (RedALyC).

Paralelo a isto, os investimentos na qualidade e na busca de indexadores que ampliassem a visibilidade e o consumo da revista sempre foi uma constante das Coordenadoras de Pós-Graduação do PEN/UFSC, assim como das editoras da revista. Assim, finalmente, em 2006, a revista passou a estar disponível on-line, em texto completo, em ambiente virtual próprio (http://www.textoecontexto.ufsc.br). No mesmo ano, passou a integrar o Portal da Biblioteca Virtual de Saúde (BVS) - enfermagem (http://www.enfermagem.bvs.br) (Bruggemann, Prado et al. 2007 )

Além disso, num esforço coletivo imenso e empreendedor, no final de 2006, a revista foi aprovada para fazer parte da coleção SciELO Brasil (http://www.scielo.br), estando disponível em texto integral e open access a partir de setembro de 2007. A partir da inclusão nesta biblioteca virtual, a Texto \& Contexto Enfermagem passou a ampliar a sua visibilidade nacional e, especialmente, internacional, o que impulsionou mais ainda a busca pela excelência da mesma. Isto significou objetivamente: maior exigência na qualidade dos manuscritos, manutenção de no mínimo 70\% de artigos originais em cada número e ampliação do número de consultores ad hoc, decorrente, principalmente, do exacerbado aumento no número de manuscritos recebido (Padilha, 2008).

A visibilidade, o livre acesso (open access), além da publicação de artigos originais resultantes de pesquisa em português, inglês e espanhol, promove uma aceitacao dos indexadores internacionais de alto impacto e, consequentemente, maior aceitação da comunidade científica sobre o periódico. Neste sentido, após a inserção na Biblioteca Virtual SciELO, em 2008, a a Texto \& Contexto Enfermagem passou a estar indexada na Base de Dados SCOPUS, o que abriu definitivamente o mercado internacional para a revista.

O número de acessos aos artigos disponibilizados on-line passou a ampliar e influenciar nos índices de impacto da revista e, finalmente, em dezembro de 2009, também foi indexada no ISI - Web of Science (Thomson, 2009). (http://science.thomsonreuters.com/mjl/publist_ssci.pdf. )

Paralelamente a estas conquistas, o Conselho Diretor da Revista Texto \& Contexto Enfermagem tomou uma decisão difícil, porém decisiva, para a continuidade da revista, em termos do crescimento vertiginoso de artigos recebidos pela mesma, ao longo do tempo. A decisão foi de terminar a publicação de números temáticos específicos, após 18 anos (19922009). Esta conduta começou a vigorar a partir de 2010. Visamos, com isto, ampliar o número de artigos em cada número, à possibilidade de submissões, assim como, melhorar as possibilidades de socialização da informação científi- 
ca oriunda das diversas áreas da saúde e enfermagem (Bruggemann; Ramos, Padilha, 2010).

Ao tentar sintetizar a história da Revista Texto \& Contexto Enfermagem procuramos salientar especialmente as conquistas e os desafios enfrentados, mas ao finalizar este texto é importante salientar que para que tudo fosse possível, foi necessário o esforço e o empreendorismo de todos os personagens que vivenciaram este processo; desde as Coordenadoras de Pós-Gradução, as Editoras, Secretarias, Bolsistas e Consultores, que, num trabalho coletivo, integrado, atento a todos os processos de mudanças e exigências, especialmente das instituicoes indexadoras, não pouparam esforços para tornar realidade esta revista reconhecida e valorizada nacional e internacionalmente.

\section{Referências}

- BRUGGEMANN OM; PRADO ML; BACKES VM; MONTICELLI, Marisa, PADILHA MI. (2007) Texto \& Contexto Enfermagem: 15 Anos de Contribuição na Socialização do Conhecimento em Enfermagem e Saude. Texto Contexto Enferm, Florianópolis, Out-Dez; 16(4): 769-72.

- BRUGGEMANN OM; RAMOS, FR, PADILHA, MI. (2010) Editorial. Texto Contexto Enferm, Florianópolis, Jan-Mar; 19(1): 11-2.

- ELSEN, I (1995). Editorial. Texto \& Contexto - Enfermagem, Florianópolis, v. 4, n. esp., 11-13.

- MANCIA, JR, PADILHA, MI, RAMOS, FS (2011) Capitulo X - A Organização Da Enfermagem Brasileira Parte 1 - A Associação Brasileira De Enfermagem (Aben). In: Enfermagem: Historia de uma Profissao. Org. PADILHA, Maria Itayra, BORENSTEIN, Miriam S., SANTOS, Iraci. Sao Paulo: Difusao Editora,.

- Ministerio da Educação. (BR). Estatísticas BRASIL [internet] [acesso em 08 Jul 2011]. Disponivel em: http:// www.capes.gov.br/estatisticas.

- PADILHA, MI (2008). Editorial. Texto Contexto Enferm, Florianópolis, Out-Dez; 17(4): 623-4.
- PADILHA, MI CS; SILVA, Guerreiro D (2002) . A temática como possibilidade de intersubjetividade - uma opção da Revista Texto\&Contexto Enfermagem. Revista Brasileira de Enfermagem (Impresso), Brasília, v. 55, 171-182,

- THOMSON R (2009). Source publication of Web of science $^{\star}$ - Social Sciences Citation Index 2009 [online]. [acesso 2009 Dez 23]. Disponível em: http://science. thomsonreuters.com/mjl/publist_ssci.pdf 